\title{
MOOC and Its Role in the Growth of Sport Media Professionals
}

\author{
Ziye Wang* \\ College of Television Communication \\ Wuhan Institute of Physical Education \\ Wuhan, P. R. China
}

\author{
Bin Hao \\ College of Television Communication \\ Wuhan Institute of Physical Education \\ Wuhan, P. R. China
}

\begin{abstract}
Aiming at the career demands and growth requirement of sport media professional, from a system viewpoint, the paper inquires into the tendency of web-based learning, and discusses MOOC from the angles of origination, construction, performance, organization, application, and serviceability. By completing value analysis of MOOC, the function, cost, value and their corresponding relations are probed, and some useful conclusions are drawn that not the only way of improving efficiency while reducing total cost is impactful, but lots of methods based on a tradeoff are similarly effective, which are available to promote the progress the growth of sport media professional talent.
\end{abstract}

Keywords-MOOC; web-based learning; sport media professional

\section{INTRODUCTION}

Internet brings people lots of advantages and convenience in life and study. As a typical representative mode of web-based teaching and learning, MOOC (Massive Open Online Course) gets a fast spread and universal popularization in the world which is taken as an effective way to accomplish education along with the mushroom growth and rapid progress of information technology, pedagogy, educational psychology, teaching methodology, etc. It is obvious that the online learning ways are quite available to help people, including sport media professional grow up steadily and continuously.

\section{WeB-BAsed LEARNING SySteM}

\section{A. The concept and features of web-base learning}

From a systematic perspective, web-based learning is considered as a series of activities of study by means of internet on the ways of autonomic learning and consultative learning which has three features:

(1) sharing the rich networked learning resources

(2) adopting individual's self-study and negotiation learning as the main modes

(3) breaking the limitation of time and space [1].

The distance learning system uses computer and communication technologies to remove the restrictions of time and space, so that students can get online learning at anytime and anywhere. It can also apply computer multimedia technology to enhance the display and interaction of teaching material [2]. Also, it can provide a fast communication interactive media, and strengthen the interaction of learner with the outside world, experts, teachers, and other students [3].

\section{B. Web-based learning platform}

Web-based learning platform is an important form of online education development, and the carrier of web-based instruction. As the computer network goes into people's life, there emerges a trend of web-based learning supported by the Internet environment. With the changing concept of studying, more and more learners have shown the greatest interest on web-based learning.

Learning materials can be updated at anytime, learners can freely access the information they need, let learner interact with teachers and/or other learners at the same time. It makes up the shortcomings of traditional distance learning compared the students' learning effectiveness in conventional classroom learning and web-based learning environment.

\section{Web-based course and learning environment}

Learning materials can be updated at anytime, learners can freely access the information they need, let learner interact with teachers and/or other learners at the same time [4]. It makes up the shortcomings of traditional distance learning compared the students' learning effectiveness in conventional classroom learning and web-based learning environment. The results indicated a better performance in web-based learning group than in classroom group.

The quality of this kind of online course is one of the crucial factors which influence the effect of web-based learning decisively. The three main characteristic variables exert great influence on the quality of the remote learning, i.e., independent learning ability, learning style as well as learning motivation. The environment of web-based learning gets greatly optimized the independent learning process and has many advantages to promote the development of self-regulated ability. The impetus and development of the internet-based teaching system can be traced back from distance education to correspondence teaching. Through the carry forward by a great deal of scholars and educationists, distance learning has become a new trend and a field of educational research. Supporting by the development of the computer network, it makes distance learning improved by using new media to enhance the delivery and interaction of information between teachers and learners. Accordingly, web-based learning can be defined as "technology-based learning in which learning 
materials are delivered electronically to remote learners via a computer network".

\section{MoOc, A Kind of Web-BAsed LeARning}

\section{A. MOOC and its texture}

MOOC is an advanced web-based teaching and learning mode and is a type of large-scale, open-access classes instructed by university faculty via the internet with a variety of contents such as weekly lecture videos/webcasts, online assessments, discussion forums, and even live video chat discussions and help sessions.

MOOCs are classes delivered in an online environment with important differences from previous approaches to online education which are able to serve as an outlet for worldwide university outreach, expanding avenues for providing free, credible information to the general public.

\section{B. Origination of $M O O C$}

Usually, the year 2011 is called the beginning or dayspring of MOOC era, the term MOOC had great social influence, and the media reflected the success of this type of course. At the same time, the number of courses grew, as well as the funding allocated to the creation of courses and platforms (with the participation of universities) specialized in the management, support and offering of MOOCs.

The crucial factor in the great impact of MOOCs is the number of enrolled learners, for some courses representing hundreds of thousands of people. This contributed to increasing the popularity and influence of the courses, which in turn increased the number of students enrolled.

\section{Main attractions of MOOC}

The attractive factors of MOOC are as follows:

A learner may interpret a dream of entering a prestigious university by taking study on MOOC offered by the famous college and brilliant teachers, which makes the person who is not able to get a chance to be enrolled in that great university particularly excited.

A learner is able to get his/her value realization and qualification certificate after completing all the teaching procedures, e.g. watching lecture video, reading the given material, participating discussion online, finishing homework and pasting tests and examination. This is affordable and effective for those people who are c their post.

Positive interaction on the curriculum platform is effective and helpful for the people enrolled on the course studying. They may be scattered around the world and never meet each other, but they can communicate freely on the plat without barrier. This makes them feel great and is unimaginable in the past [5].

Simulating classroom learning and interactive communication bring the learners special experience and excitation, which is the greatest attraction to the MOOC and separate course designers to make the course study increasingly on-the-spot experience to attracting learners to participate in various activities.

MOOCs break the history of educational fees. Offering a low threshold mode of higher education popularization without any payment (if a person does not need a paper certificate), improves the fairness of education vastly [6].

\section{Value analysis of MOOC learning}

Referencing a basic formula from value engineering,

$$
V=F / C \text {, }
$$

It is clear that the value equals to the ratio of function to cost. Introducing it into the process of online education analysis, replacing the function $F$ by learning effect, marked as $E$, the formula is changed into a similar type as:

$$
V=E / C \text {. }
$$

The cost is viewed as the combination of two parts, money and time. Then the total cost $C_{T}$ is sum of cost of money $C_{M}$ and the cost of time $C_{T}$, shown as:

$$
C_{T}=C_{M}+C_{T}
$$

Denoting $V$ as $V_{M O O C}$, or $V_{M}$,

$E$ as $E_{\text {LEARNING }}$, or $E_{L}$,

the formula becomes:

$$
V_{M}=E_{L} / C_{T}
$$

From it we can see that there so many ways to improve the value of MOOC, such as:

If the learning effect is improved, while the cost reduced, then the value of MOOC is absolutely enlarged:

$$
E_{L} \uparrow, C_{T} \downarrow \text {, }
$$

Then:

$$
V_{M} \uparrow
$$

When the efficiency remains unchanged, but cost is debased, then the value stepped up:

$$
\mathrm{E}_{\mathrm{L}} \rightarrow, \mathrm{C}_{\mathrm{T}} \downarrow
$$

Then:

$$
\mathrm{V}_{\mathrm{M}} \uparrow
$$

If the learning effect is raised, but the cost keep the same, and then the value augment in a given amount:

$$
E_{L} \uparrow, C_{T} \rightarrow \text {, }
$$

Then:

$$
V_{M} \uparrow
$$

If the efficiency has a big aggrandize, at the same time the cost is added to a certain extent, the total value enhanced correspondingly:

$$
E_{L} \uparrow \uparrow, \mathrm{C}_{\mathrm{T}} \uparrow,
$$

Then:

$$
V_{M} \uparrow
$$

In case of a decrease of learning efficiency, while the cost falls down sharply, the value of MOOC is still heightened:

$$
E_{L} \downarrow, C_{T} \downarrow \downarrow
$$

Then:

$$
V_{M} \uparrow
$$

The analysis above presented that there in not only one way to promote the value of MOOC. The best benefit could be got by different means on the base of tradeoff [7]. 
It also illustrated that a scientific and complete knowledge system should be designed which brings the course a clear context and framework. The content should be streamlined, and a logical link and connection between separate knowledge points, even their relationship should be got and revealed to help the learner understand knowledge and think questions and issues systematically and wisely.

\section{The Growth Of Sports Media Professionals}

\section{A. Essential demands of sports media professionals}

Sports media professionals (SMPs) have some specific career demands. Basically, they have to master knowledge of sport games and activities as comprehensive as possible, to have a wisdom mind, sharp perspective, quick and accurate judgment, precise and reasonable expression, warm and moderate interaction with the audience, and to be able to grasp new skills and techniques. Along with the development of science and technology, new style of media forms and communication tools, mode of propagation spring up constantly [8]. Keeping pace with the times is definitely essential for the professionals of this field to progress and improve continually. The career demands of them can be inducted as three aspects, which are personal quality, professional quality and professional skills.

Personal qualities include:

(1) Social responsibility which is indispensable for a media worker who was usually viewed as a gate-keeper of public opinion;

(2) Humanistic quality, the internal character of a person with the core of humanity spirit of people-oriented or people-centered;

(3) New media thinking, which is vital for media professionals at the information era;

(4) Creative spirit, i.e. new viewpoint, new thinking and new method, to help media staff changing their mind to do work more effective and more valuable.

As for the professional quality, knowledge of sports and game are essential definitely. Besides, language skill is the base, while commentary ability enable sports media professionals do their job more powerful.

\section{Professional skills include:}

(1) Spot control ability, when the sport game is extremely fierce, audiences' may lose their temper where the media work, e.g. commentator should try his best to lead the fans chill out and calm down; thus

(2) Interact with audience actively and initiatively are serviceable. Making the spot warm when it is cold and cheerless, while turning it down when it is too turbulent and tempestuous in a kind way is the duty of SMPs;

(3) To be able to accomplish those work such as interview, producing and broad-casting concurrently (Jack of all trades) is the basic requirement of the sports media professionals of this time; while,

\section{(4) Proficient use of new media tools is needful for SMPs.}

\section{B. New demands of SMPs}

In the times of new media, multiple-media convergence, demands for news media, including sport media practitioners show the characteristics of multi-level, diverse and compound. Thus, the cultivation of sport media professionals should be set on the concept of innovation integration facing the requirement of employer unit and the fierce competition in the media market.

\section{MOOC for SMPs}

Nowadays MOOC has had a huge impact on the educative chain and the education business. Seeing from its developmental course, it has not only attracted more and more attentions, but also enlarged its influences.

MOOCs are usually viewed as a sonic storm of education and learning, which seems to be a fenceless university opened to the public all over the world. It is a new trend and hotspot of education and spread quickly in the world. People get into the course any-where with the internet and electronic reading tools (computer or mobile) by watching video of teacher's lecture, reading materials on the course website. They interact with the teacher and other learners, so as to make their mind clear by discussion even contesting, arguing at the interactive zone. For SMP, a special area well- designed on the website of the course is capable to offer the learners to show their work, and cause comment and criticism by each other.

MOOC is a useful channel to connect teacher and the learners, so as to make their mind clear by discussion even contesting, or arguing at the interactive zone. For SMP, a special area well- designed on the website is capable to offer the learners to show their work in the form of video, audio or others forms, and cause comment and criticismby each other.

In the times of new media, multiple-media convergence, demands for news media, including sport media practitioners show the characteristics of multi-level, diverse and compound. Thus, the cultivation of sport media professionals should be set on the concept of innovation integration facing the requirement of employer unit and the fierce competition in the media market.

\section{CONCLUSION}

Web-based learning, including MOOC is a by-product of science and technology. The wide variety of materials are presented on that platform in an effective, structured, organized manner, thus enabling users to acquire, understand, and process information as easily as possible. SMPs in current era are claimed to be an interdisciplinary, tip-top professional talent with comprehensive ability. By learning MOOC in a web-based environment, they are able to attain useful knowledge and get a great growth.

\section{REFERENCES}

[1] Petra S F, Jaid in J H, JSH Quintus Perera, et al. Supporting students to become autonomous learners: the role of web-based learning[J]. International Journal of Information \& Learning Technology, 2016, 33(4):263-275.

[2] Kotevsk Z, Tasevska I. Evaluating the Potentials of Educational Systems to Advance Implementing Multimedia Technologies[J]. International Journal of Modern Education \& Computer Science, 2017, 9(1):26-35.

[3] Kotevsk Z, Tasevska I. Evaluating the Potentials of Educational Systems to Advance Implementing Multimedia Technologies[J]. International Journal of Modern Education \& Computer Science 9(1), 26-35 (2017).

[4] Cheng F F, Chiu C C, Wu C S, et al. The influence of learning style on satisfaction and learning effectiveness in asynchronous web-based learning system[J]. Library Hi Tech, 2017, 35(6):00-00. 
[5] D Nandi, M Hamilton, J Harland. What Factors Impact Student Content Interaction in Fully Online Courses[J]. International Journal of Modern Education and Computer Science 7(7), 28-35, (2015).

[6] Alkhathlan A A, Al-Daraiseh A. An Analytical Study of the Use of Social Networks for Collaborative Learning in Higher Education[J]. International Journal of Modern Education \& Computer Science 9(2), 1-13, (2017).
[7] Arshia A Khan, Janna Madden. Speed Learning: Maximizing Student Learning and Engagement in a Limited Amount of Time[J]. International Journal of Modern Education and Computer Science,2016, 8(7):22-30.

[8] Li Yin. Cultivation of inter-disciplinary media talent under the background of convergence Media[J]. Beijing Education (02), 17-18 (2015). (In Chinese) 